\title{
Potential Role of Proprotein Convertase SKI-1 in the Mineralization of Primary Bone
}

\author{
Jeff P. Gorski ${ }^{a}$ Nichole T. Huffman ${ }^{a}$ Chaoying Cui $^{c}$ Ellen P. Henderson ${ }^{a}$ \\ Ronald J. Midura ${ }^{b}$ Nabil G. Seidah ${ }^{d}$ \\ ${ }^{a}$ Department of Oral Biology, School of Dentistry, University of Missouri at Kansas City, Kansas City, Mo., and \\ ${ }^{b}$ Department of Biomedical Engineering, Lerner Institute, Cleveland Clinic, Cleveland, Ohio., USA; \\ ${ }^{\mathrm{c}}$ Tibet University Medical College, Lhasa, Tibet, China; ${ }^{\mathrm{d}}$ Clinical Research Institute of Montreal, Montreal, Que., Canada
}

\section{Key Words}

Biomineralization $\cdot$ Bone cell biology $\cdot$ Intramembranous

bone $\cdot$ Calcification mechanisms $\cdot$ Extracellular

matrix $\cdot$ Laser microscopy $\cdot$ Proteins $\cdot$ SKI- $1 \cdot$ Protease site-1) is a membrane-bound serine protease inhibitable by AEBSF. We show here for the first time that mineralizing UMR 106 cells express a 98-kDa active, soluble form of SKI-1 within BMF. In contrast, nonmineralizing UMR cells appear to differentially process SKI- 1 into smaller immunoreactive frag-

\begin{abstract}
The biochemical mechanism controlling nucleation of mineral crystals in developing bone, along with the growth and propagation of these crystals once formed, remains poorly understood. To define the nucleation mechanism, a proteomics analysis was begun on isolated biomineralization foci (BMF), sites of initial crystal nucleation in osteoblastic cell cultures and in primary bone. Comparative analyses of the protein profile for mineralized BMF with that for total osteoblast cultures revealed the latter were enriched in several proteins including BAG-75 and BSP, as well as fragments of each. When 12 protease inhibitors were added separately to UMR 106-01 osteoblastic cultures, only the serine protease inhibitor 4-(2-aminoethyl) benzenesulfonyl fluoride hydrochloride (AEBSF) blocked cleavage of BAG-75 and BSP, and prevented mineral crystal nucleation within BMF. Consideration of the specificities of the inhibitors tested and the fact that AEBSF inhibition was not dependent upon inclusion of FBS in the culture media indicated that mineral nucleation does not require serine protease plasmin, thrombin, kallikrein, urokinase, C1s or furin. In contrast, SKI-1 (S1P or
\end{abstract}

\begin{tabular}{ll}
\hline Abbreviations used in this paper \\
\hline 1,25-D3-MARRS & $\begin{array}{l}\text { membrane-associated, rapid response } \\
\text { steroid-binding protein } \\
\text { 4-(2-aminoethyl) benzenesulfonyl fluoride } \\
\text { hydrochloride }\end{array}$ \\
AEBSF & bone acidic glycoprotein-75 \\
BAG-75 & $\begin{array}{l}\text { 3-glycerolphosphate } \\
\text { biomineralization foci }\end{array}$ \\
BMF & bone morphogenic protein-1 \\
BMP-1 & bovine serum albumin \\
BSA & bone sialoprotein \\
BSP & dentin matrix protein-1 \\
dithiothreitol \\
DMP-1 & ethylenediaminetetraacetic acid \\
fetal bovine serum & proprotein convertase \\
EDTA & procollagen C proteinase enhancer protein 1 \\
FBS & site-1-protease \\
PC & sodium dodecyl sulfate \\
PCOLCE & subtilisin kexin isozyme-1 \\
S1P & sterol regulatory element binding proteins \\
SDS &
\end{tabular}

\section{KARGER}

() 2008 S. Karger AG, Basel

Fax +4161306 1234

E-Mail karger@karger.ch

www.karger.com
Accessible online at: www.karger.com/cto
Dr. Jeff P. Gorski

Bone Biology Program, Department of Oral Biology, School of Dentistry

University of Missouri at Kansas City, 625 East 25th Street

Kansas City, MO 64108 (USA)

Tel. +1 816235 2537, Fax +1 816235 5524, E-Mail gorskij@umkc.edu 
ments $(<35 \mathrm{kDa})$. These findings suggest that SKI-1 plays a direct or indirect role in assembly of functional nucleation complexes containing BAG-75 and BSP and their fragments, thus facilitating initial mineral nucleation within these biomineralization foci.

Copyright $\odot 2008$ S. Karger AG, Basel

\section{Introduction}

Primary or woven bone is believed to be 'disorganized' by virtue of the appearance of its collagenous matrix. While controversy still exists over whether mineralization is initiated by collagen, by matrix vesicles, a combination of both or by other mechanisms, mineralization of primary bone is less well studied. Primary bone is an embryonic precursor of lamellar bone; however, fixed fractures heal and bone gained through biomechanical adaptation also form primarily via a woven bone intermediate [Turner et al., 1994; Mark et al., 2004]. Contrasted with compact lamellar bone, primary bone is distinguished by the speed of its formation and mineralization estimated to be 6 times faster [Kimmel and Jee, 1980]. A careful examination of noncollagenous components and cellular responses of primary and lamellar bone caused us to propose that each utilizes a different, but related, osteogenic program [Gorski, 1998]. We have identified a specific biomarker (bone acidic glycoprotein-75, BAG75 ) in rapidly developing primary bone and osteoblastic cell cultures which spatially defines focal sites which will become mineralized up to 2 days later (biomineralization foci, BMF) [Gorski et al., 2004; Midura et al., 2004].

BMF are identifiable in several osteoblastic culture models where they appear as extracellular spherical 15to $25-\mu \mathrm{m}$ diameter complexes containing several size populations of vesicles [Midura et al., 2004]. In addition to BAG-75, bone sialoprotein (BSP) also becomes associated with BMF after addition of a phosphate source to the culture. BSP is a known nucleator of calcium phosphate crystal formation [Goldberg et al., 1996]. BAG-75 contains over 40 phosphate groups per mole, can bind up to 180 atoms of calcium per mole and is capable of self-associating into $12-\mathrm{nm}$ fibrils stretching up to $1 \mu \mathrm{m}$ in length [Chen et al., 1992]. A 50-kDa fragment of BAG-75 is also present in bone and serum [Gorski et al., 1990]. Interestingly, the serum level of the $50-\mathrm{kDa}$ fragment appears to correlate with the rate of bone formation in vivo [Gorski, unpubl. result].

Most cells express subtilisin-like serine proteinases, the proprotein convertases (PCs), which mediate the pro- teolytic processing of secretory glycoproteins and the regulated release of membrane-bound transcription factors such as ATF6 and SREBPs [Seidah and Prat, 2002; Pasquato et al., 2006]. The prototypic basic amino acidspecific PC is furin [Seidah and Chretien, 1999], which was shown to activate BMP-1/Tolloid [Leighton and Kadler, 2003]. Activated BMP-1 has been shown to catalyze the cleavage of DMP-1 into $57-$ and $37-\mathrm{kDa}$ fragments [Steiglitz et al., 2004].

Based on our initial studies [Gorski et al., 2004; Midura et al., 2004], we propose a unifying model for mineralization in primary bone that is initiated within BMF and regulated by osteoblastic cells (fig. 1). This model reconciles many of the existing ideas on mineralization into a single pathway that includes both active (cell-mediated) and passive (physicochemical) processes as well as matrix vesicle- and collagen-mediated mineralization mechanisms. Figure 1 summarizes this hypothesis, which provides a conceptual framework for our ongoing studies.

\section{Experimental Procedures}

\section{Materials}

Antibodies were from several sources: nonimmune rabbit IgG (EMD Biosciences, Inc.), anti-BAG-75 No. 503 (anti-peptide antibody) rabbit serum [Gorski et al., 1990], anti-SKI-1 antibody [Elagoz et al., 2002], anti-BAG-75 No. 504 (anti-protein antibody) rabbit serum [Gorski et al., 1990], anti-bone sialoprotein LF-100 antiserum (Larry Fisher, National Institute of Dental and Craniofacial Research, NIH) and monoclonal anti-BSP [WV1D1(9C5)] antibody (NIH Developmental Studies Hybridoma Bank, University of Iowa).

\section{Cell Culture and Treatment with Protease Inhibitors}

UMR 106-01 BSP cells were passaged and cultured at $37^{\circ} \mathrm{C}$ and $5 \%$ carbon dioxide as described previously [Wang et al., 2000] and updated briefly here. Cells were seeded at a density of $1.0 \times$ $10^{5}$ cells $/ \mathrm{cm}^{2}$ in growth medium [Eagle's MEM supplemented with Earle's salts, 1\% nonessential amino acids (Sigma-Aldrich Co.), 10 mM HEPES, pH 7.2, and 10\% FBS (Hyclone)]. After 24 h, the medium was exchanged with growth medium containing 0.5\% BSA (catalog No. A-1933; Sigma-Aldrich Co.) instead of FBS. Sixty-four hours after plating, the culture medium was exchanged with mineralization media [growth medium containing either $0.1 \%$ BSA or $10 \%$ FBS and $7 \mathrm{mM} \beta$-glycerolphosphate (BGP)]. Cultures were then incubated for an additional $24 \mathrm{~h}$, at the end of which $(88 \mathrm{~h})$ the cells were either subjected to MTT assay or fixed in $70 \%$ ethanol and then extracted for protein. In some experiments, protease inhibitors, including the serine protease inhibitor (4-(2-aminoethyl)-benzenesulfonylfluoride hydrochloride (AEBSF; EMD Biosciences Inc.), were added to cultures at $64 \mathrm{~h}$ after plating in mineralization media. Alternatively, AEBSF was added at $44 \mathrm{~h}$ after plating; inhibitor was then removed and 


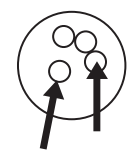

Matrix vesicles

BMF or mineralization domains provide a

protected environment that is enriched in promoters of mineralization and excludes inhibitors.

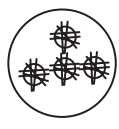

Nucleation of hydroxyapatite crystals occurs in matrix vesicles as an active cell-mediated process within the BMF.
Growth and expansion phase (passive/physicochemical)

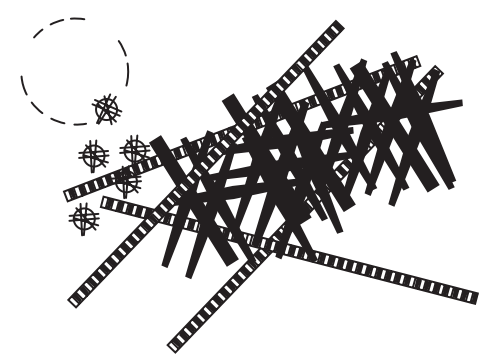

Dissolution of the BMF barrier function exposes the hydroxyapatite crystals to the outside environment and allows growth and expansion by passive physicochemical mechanisms. This phase requires ECM components, such as collagen (striped bars) and fibronectin.
Hypothetical steps in BMF-mediated mineralization

Phase 1:

1. Formation of immature BMF containing BAG-75 and some vesicles

2. Maturation by incorporation of additional components, e.g. BSP, AP and additional vesicles

3. Loading of separate vesicles with $\mathrm{Ca}^{+2}$ and $\mathrm{Pi}$

4. Fusion of vesicles and nucleation of initial mineral

Phase 2:

5. Dissolution of BMF barrier

6. Seeding of collagen fibril calcification: requirement for additional components?

Fig. 1. Proposed 2-stage model of biomineralization of primary bone. Immature BMF assemble from proteins and vesicles released from osteoblastic cells and represent the physical sites of initial mineralization nucleation within a developing or healing bone. This process is believed to be under cellular regulatory control. Growth and expansion of this initial mineral phase occurs when calcospherulite particles are subsequently released from mineralized BMF and seed the territorial collagenous matrix. This process is believed to be a passive physiochemical process. ECM = Extracellular matrix; $\mathrm{AP}=$ alkaline phosphatase; $\mathrm{Pi}=$ inorganic phosphate.

exchanged for mineralization media at $64 \mathrm{~h}$ and the amount of mineralization analyzed at $88 \mathrm{~h}$.

Primary mouse osteoblasts were isolated from calvaria of 5 - to 7-day-old mice using a modification of a published method [Huffman et al., 2007]. Calvaria were aseptically harvested and 4 sequential 20-min digests were performed in $0.05 \%$ trypsin $/ 0.2 \%$ collagenase in Hanks' balanced salt solution. Fractions 2 through 4 were pooled, centrifuged and resuspended in $\alpha$-MEM containing 10\% FBS, $2 \mathrm{mM}$ L-glutamine, $100 \mu / \mathrm{ml}$ penicillin and $30 \mu \mathrm{g} /$ $\mathrm{ml}$ gentamicin ( $\alpha$-growth medium). Per T-75- $\mathrm{cm}^{2}$ flask, $2 \times 10^{6}$ cells were plated and allowed to reach confluency (3-4 days). Confluent flasks were then trypsinized and plated into 12- or 24well culture dishes for experiments at a density of 20,000 cells per $\mathrm{cm}^{2}$ growth area using media and supplements as described above. At confluency, the media were changed to $\alpha$-MEM containing 5\% FBS, $50 \mu \mathrm{g} / \mathrm{ml}$ ascorbic acid, $5 \mathrm{~mm}$ BGP and other supplements as described above. BGP was omitted from some wells which served as unmineralized controls. In order to test the effect of AEBSF, identical duplicate cultures were treated on days 3,6 or 9 with $0.003-0.1 \mathrm{~mm}$ AEBSF. On day 12 after plating, one set of cultures was incubated with MTT as described below to determine cell viability. A second set of cultures was fixed on day 12 with $70 \%$ ethanol and processed for quantitative alizarin red S staining as described below.

\section{MTT Assay}

Culture wells were washed with Eagle's MEM supplemented with Earle's salts and then incubated with a solution of $0.5 \mathrm{mg} / \mathrm{ml}$ MTT (3-(4,5-dimethylthiazol-2-yl)-2, 5-diphenyl-2 H-tetrazolium bromide) in Eagle's MEM for $1-2 \mathrm{~h}$ at $37^{\circ} \mathrm{C}$ [Huffman et al., 2007]. Residual MTT solution was removed, the cells disrupted by mixing briefly with dimethylsulfoxide, and free, reduced dye was read at 490 or $540 \mathrm{~nm}$ in a spectrophotometer.

\section{Quantitation of Mineralization}

After fixation in $70 \%$ ethanol, the cell layer was rinsed and stained with alizarin red S dye [Huffman et al., 2007]. The same procedure was also used for serum-depleted cultures with the following modified washing protocol, that is, the stained cell layer was rinsed once with $1 \mathrm{mM}$ HEPES in nanopure water. A standard curve for alizarin red $S$ dye was constructed for each analysis and the amount of bound dye per culture well was determined.

\section{Statistical Methods}

All statistical tests were performed using Sigma Stat 3.1 software (Systat Software Inc.). A one-way analysis of variance test was used to determine if a statistical difference existed between the viability of UMR 106-01 cultures or the amount of mineral deposited. Subsequent pair-wise multiple comparison tests were performed with the Student-Newman-Keuls or Kruskal-Wallis method. 


\section{Extraction of Cell Layer Fraction}

Cells were dislodged by scraping and then extracted with 75 $\mathrm{mM}$ potassium phosphate buffer $(\mathrm{pH} 7.2)$, containing $10 \mathrm{mM}$ CHAPS, $75 \mathrm{~mm}$ sodium chloride, $50 \mathrm{~mm}$ tetra sodium EDTA, 10 $\mathrm{mM}$ benzamidine hydrochloride, $2 \mathrm{mM}$ DTT and $0.02 \%$ sodium azide for $1 \mathrm{~h}$ at $4^{\circ} \mathrm{C}$. Each extract was then homogenized briefly using a motorized pestle and clarified by ultracentrifugation at $30,000 \mathrm{rpm}$ for $1 \mathrm{~h}$ at $4^{\circ} \mathrm{C}$ in an SW 50.1 rotor prior to use. Conditioned media was immediately heated to $95^{\circ} \mathrm{C}$ for $5 \mathrm{~min}$ to inactivate protease activity and frozen at $-80^{\circ} \mathrm{C}$ until analyzed.

\section{Laser Capture Microscopy}

UMR cells were grown as usual on Fisher Plus microscope slides (Fisher Scientific Inc.), fixed and stained with alizarin red $S$ dye. Immediately prior to laser capture, slides were dehydrated through a graded series of ethanol washes and xylene rinses. Dried slides were stored at $-20^{\circ} \mathrm{C}$ in a sealed box with desiccant until used. Mineralized BMF were collected onto standard caps using an Arturus Pixel IIe microscope. Collection films were pooled and stored in $70 \%$ ethanol at $-20^{\circ} \mathrm{C}$ until approximately 6,200 BMF were collected. Laser microscopy-captured BMF were then mixed in $70 \%$ ethanol to dislodge the purple-stained particles which were then microfuged to remove the ethanol. BMF pellets were extracted twice sequentially over a 2 -day period at $4^{\circ} \mathrm{C}$ with $1.1 \mathrm{ml}$ of $0.1 \mathrm{M}$ Tris-acetate buffer ( $\mathrm{pH} 7.8$ ) containing $0.5 \%$ octyl-glucoside, $0.05 \%$ SDS, $0.05 \mathrm{M}$ EDTA and $0.02 \%$ sodium azide. Extracts were then dialyzed first against $0.01 \mathrm{M}$ Tris-acetate buffer (pH 7.8) containing $8 \mathrm{M}$ urea, $0.05 \%$ SDS, $0.1 \%$ octyl-glucoside, $0.05 \mathrm{M}$ EDTA, and second against $0.01 \mathrm{M}$ Tris-acetate buffer ( $\mathrm{pH} 7.8$ ) containing $8 \mathrm{M}$ urea, $0.05 \%$ SDS and $0.1 \%$ octyl-glucoside. Controls consisted of glass slides containing the total cell layer fractions from $+\mathrm{BGP}$ or $-\mathrm{BGP}$ cultures; control slides were extracted using a similar protocol. The resultant dialyzed extracts were used for comparative blotting studies where identical protein amounts were loaded per gel lane.

\section{Protein Determination}

Protein concentration of BMF extracts was determined using the Non-Interfering Protein Assay by Geno Technology Inc.

\section{Western Blotting and Chemiluminescence Detection}

Extracts and media fractions prepared as described above were electrophoresed under reducing conditions on 4-20\% linear gradient gels (ISC BioExpress) and electroblotted onto PVDF membranes (Millipore Corp.) for $2 \mathrm{~h}$ at $100 \mathrm{~V}$ [Huffman et al., 2007]. The transfer buffer was composed of 10 mM CAPS buffer ( $\mathrm{pH} 11.0)$ containing $10 \%$ methanol. Blots were processed as described previously [Huffman et al., 2007]. Films were digitized using a flat bed scanner.

\section{Results}

\section{Biomineralization Foci}

Previous work has identified BMF as the sites of initial mineral crystal nucleation within osteoblastic cell cultures and in primary bone [Gorski et al., 2004; Midura et al., 2004; Huffmann et al., 2007]. Immunostaining and

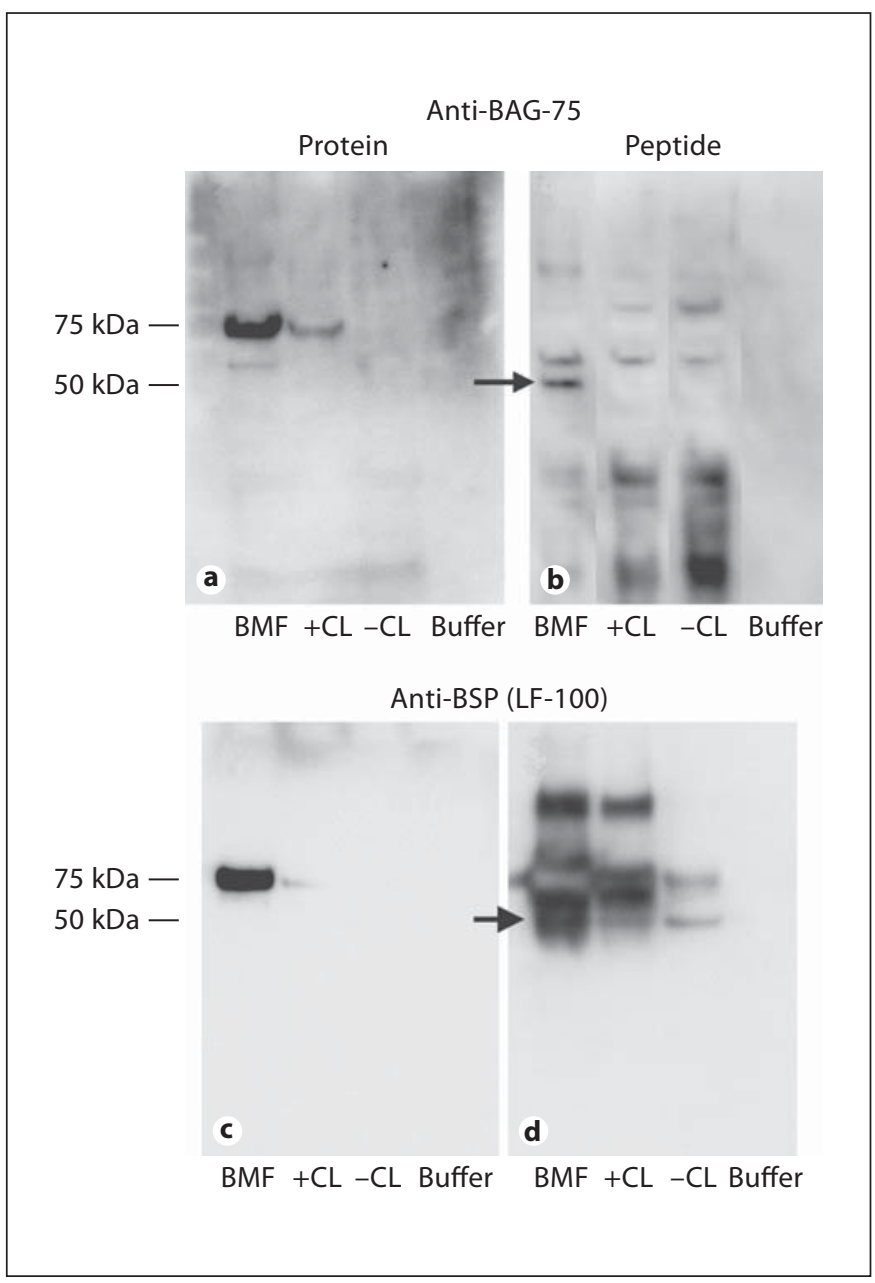

Fig. 2. Comparative immunostaining of laser capture microscope-isolated BMF versus total cell layer fractions demonstrates an enrichment of BAG-75 and BSP and their fragments. Protein extracts from laser microscope-captured BMF, cell layer fractions and a buffer control were electroblotted onto PVDF membrane and developed with anti-BAG-75 or anti-BSP antibodies. Arrows indicate 45 - to $50-\mathrm{kDa}$ fragments of BAG-75 and of BSP enriched in BMF extracts over that in the $+\mathrm{CL}$ total cell layer. The amount of protein loaded onto gel lanes was $6.5 \mu \mathrm{g}(\mathbf{a}-\mathbf{c})$ and $13 \mu \mathrm{g}(\mathbf{d})$. d The blot was intentionally overdeveloped to detect the BSP fragment. Antibodies used: anti-BAG-75 protein antibody (No. 504), anti-BAG-75 peptide antibody (No. 503) and anti-BSP antibody (LF-100). BMF = Extract of laser microscope-captured BMF; $+\mathrm{CL}=$ extract of total cell layer from BGF-treated cultures; $-\mathrm{CL}=$ extract of total cell layer from cultures not treated with BGF; buffer = extraction buffer alone. From Huffman et al. [2007], reprinted with permission of the American Society for Biochemistry and Molecular Biology. 
Table 1. Effect of protease inhibitors on mineral nucleation within BMF in UMR-106 cultures

\begin{tabular}{|c|c|c|c|}
\hline Aprotinin & trypsin, chymotrypsin and plasmin & $0-3 \mu \mathrm{g} / \mathrm{ml}$ & no \\
\hline Antipain & papain and trypsin, plasmin & $100 \mu \mathrm{M}$ & no \\
\hline C1s inhibitor & activated complement protein $\mathrm{C} 1 \mathrm{~s}$ & $0.1-100 \mu \mathrm{g} / \mathrm{ml}$ & no \\
\hline Elastatinal & elastase and elastase-like proteases & $100 \mu \mathrm{M}$ & no \\
\hline GM 6001 & matrix metalloproteinases $2,3,8$ and 9 & $10 \mu \mathrm{M}$ & no \\
\hline Hexa-D-arginine & furin & $1-10 \mu \mathrm{M}$ & no \\
\hline Hirudin & thrombin & $0.5-10$ ATU & no \\
\hline Leupeptin & trypsin-like proteases and some cysteine proteases & $100 \mu \mathrm{M}$ & no \\
\hline Pefabloc PL & plasmin and plasma kallikrein & $1-100 \mu \mathrm{M}$ & no \\
\hline
\end{tabular}

From Huffman et al. [2007], reprinted with permission of the American Society for Biochemistry and Molecular Biology. One antithrombin unit (ATU) will neutralize $1 \mathrm{NIH}$ unit of thrombin at $37^{\circ} \mathrm{C}$, based on direct comparison with an NIH thrombin reference standard.

electron microscopy indicate that BMF are heterogeneous complexes of proteins as well as phospholipid-containing vesicles enriched in BAG-75 and BSP proteins. $\mathrm{BMF}$ are detectable in cultures prior to addition of phosphate; following addition of a phosphate source, nucleation occurs exclusively within BMF.

To identify the proteins regulating mineral nucleation, we have isolated mineralized BMF using laser capture microscopy and begun to characterize the BMF proteome [Huffmann et al., 2007]. Initial results have shown, as predicted, that the biomarkers BAG-75 and BSP are highly enriched within isolated BMF (fig. 2). This result validated the use of laser capture microscopy to purify mineralized BMF. Unexpectedly, BMF were also enriched in $50-\mathrm{kDa}$ fragments of BAG-75 and BSP (fig. 2). Since these fragments were predominantly localized to BMF, this finding raised the possibility that proteolytic cleavage of these phosphoproteins is involved with mineralization.

\section{Serine Protease Inhibitor AEBSF Specifically Inhibits Mineralization}

In order to investigate the nature of the protease activity responsible and the relationship of BAG-75/BSP cleavage with mineral nucleation within BMF, we tested a series of 12 protease inhibitors (table 1) in the UMR 106-01 osteoblastic cell culture model. Specifically, individual inhibitors were added to confluent cultures at $64 \mathrm{~h}$ after plating and the amount of hydroxyapatite formed within
BMF was scored $24 \mathrm{~h}$ later. UMR cultures are not competent to mineralize until $60 \mathrm{~h}$ after plating, reflecting an osteogenic differentiation process which leads to the production of spherical immature BMF structures enriched in BAG-75. Only one inhibitor, AEBSF, was found to interfere with mineral nucleation (table 1; fig. 3). AEBSF is a serine protease inhibitor which binds covalently, causing permanent inactivation. In view of the potential toxicity of AEBSF, we compared its inhibitory effect with that for overall cell viability (fig. 3a). While AEBSF specifically blocked nucleation of mineral crystals within BMF at 0.01-0.4 mM, cell viability was affected only above $1 \mathrm{mM}$. Alternatively, if cells were treated for $24 \mathrm{~h}$ with AEBSF, starting at $40 \mathrm{~h}$ after plating rather than at $64 \mathrm{~h}$, the inhibitor was 10 times less effective in blocking subsequent mineralization scored at $88 \mathrm{~h}$. Importantly, AEBSF also blocks mineralization of primary mouse calvarial osteoblastic cells with a similar sensitivity. Complete inhibition was observed whether AEBSF treatment was started on day 3, 6 or 9 after plating (data not shown), where mineralization occurs on day 12 (fig. 3b). Thus, mineralization mediated by osteoblastic cells in culture is associated with an AEBSF-inhibitable serine protease. Results from both primary and transformed osteoblastic cultures suggest a serine protease acts late in the process of mineral nucleation. Thus, mineral nucleation mediated by osteoblastic cells in culture is associated with an AEBSF-inhibitable serine protease. 


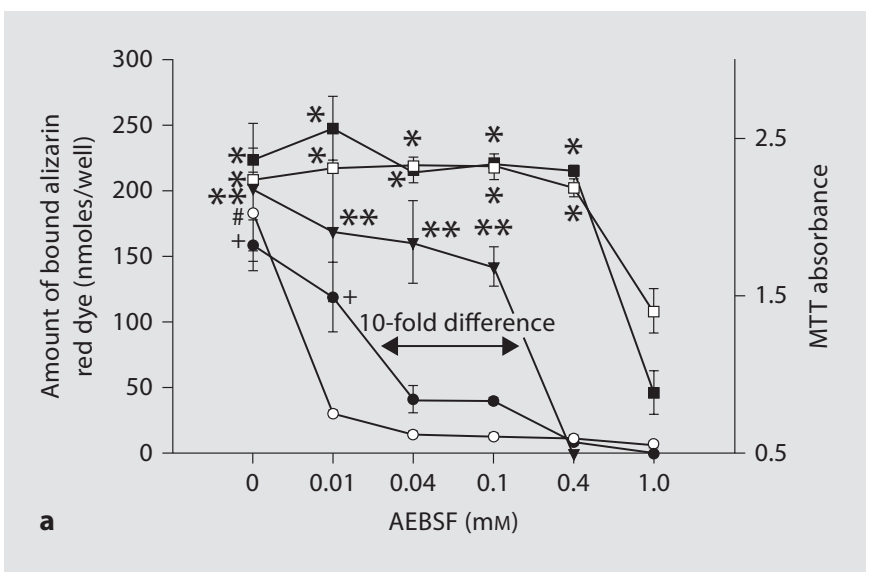

Fig. 3. AEBSF inhibits mineral nucleation both in UMR 106 osteoblastic cultures and in primary mouse calvarial osteoblasts. a With UMR cells, AEBSF blocks mineralization similarly in both serum-containing and serum-depleted conditions, while displaying higher effectiveness with mineralization-competent cultures. The amount of alizarin red $S$ bound to calcium phosphate crystals within BMF and cell viability assessed with the MTT assay were plotted versus the concentration of AEBSF added to cultures. AEBSF was present twice during the culture model, that is, 44$64 \mathrm{~h}$ and $64-88 \mathrm{~h}$ after plating. A 4 -fold increase in sensitivity was observed in converting from serum-sufficient conditions to serum-depleted conditions, while a 10 -fold increase in effectiveness was obtained when comparing $64-88 \mathrm{~h}$ versus $44-64 \mathrm{~h}$ cultures. For $64-88$ h cultures: $\square=$ MTT absorbance in serum-depleted conditions; $\mathbf{\square}=$ MTT absorbance in serum-containing media; $\mathrm{O}=$ amount of alizarin red bound in serum-depleted conditions; - = amount of alizarin red bound in serum-containing media. For 44-64 h cultures: $\boldsymbol{\nabla}=$ amount of alizarin red bound in serum-containing media. MTT assay results for 44-64 h cultures were essentially identical to those for $64-88 \mathrm{~h}$ cultures and were omitted from the graph to maintain clarity. For the MTT cell viability assays, individual results $\left({ }^{*}\right)$ were significantly different from cultures treated with $1 \mathrm{mM}$ AEBSF at a $99.9 \%$ confidence level. For alizarin red S assays on $64-88 \mathrm{~h}$ cultures, individual results were significantly different from cultures treated with 0.04 mM AEBSF $\left({ }^{+}\right)$and with $0.01 \mathrm{~mm} \operatorname{AEBSF}\left({ }^{*}\right)$ at a $99.9 \%$ confidence

\section{SKI-1 Serine Protease Is Present in BMF}

Figure 4 depicts the results of Western blotting with anti-SKI-1 N-terminal antibody and UMR 106-01 cell culture fractions. Specifically, total cell extracts from phosphate-supplemented and control cultures were compared with that for the laser capture microscope-purified BMF. It is apparent that SKI-1 is present in all mineralizing samples as a $98-\mathrm{kDa}$ soluble enzyme (fig. $4,+\mathrm{CL}$ and $\mathrm{BMF}$ ); the predominant forms in nonmineralizing cultures are smaller than $35 \mathrm{kDa}$ (fig. $4,-\mathrm{CL}$ ). Under normal conditions, SKI-1 resides in the cis/medial Golgi as

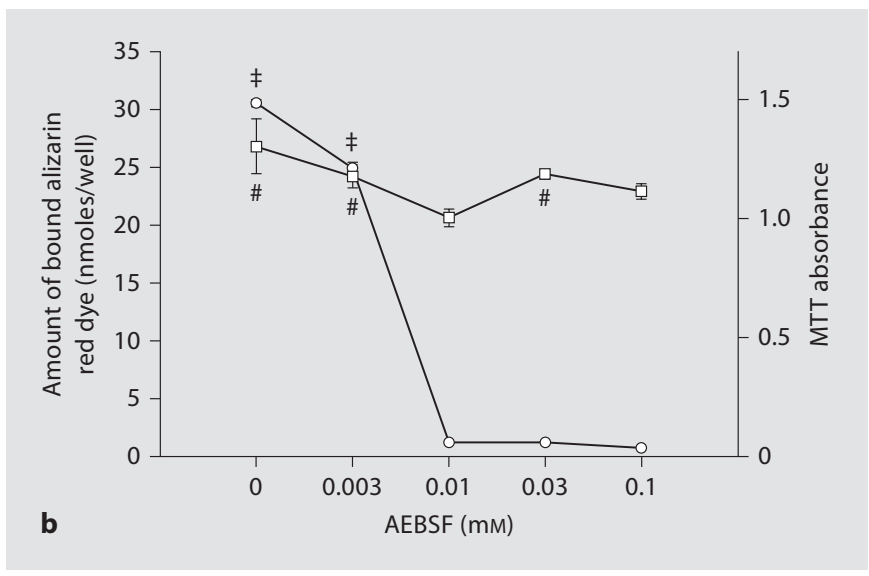

level. For alizarin red S assays on 44-64 h cultures, individual results $\left(^{* *}\right)$ were significantly different from cultures treated with $1 \mathrm{mM}$ AEBSF at a $99.8 \%$ confidence level. Results shown are representative of 4 experiments. b AEBSF inhibits mineralization within nodules of primary mouse calvarial cultures without affecting viability. MTT assay results and the amount of alizarin red $S$ bound to mineral deposits within cultures on day 12 are plotted versus the concentration of AEBSF added to cultures on day 9. $\square=$ MTT absorbance in serum-containing media; $\bigcirc=$ amount of alizarin red bound in serum-containing media. For alizarin red $S$ dye binding results for primary mouse calvarial cultures, untreated controls $\left(^{\ddagger}\right)$ and $0.003 \mathrm{mM}$ AEBSF wells $\left(^{(}\right)$were significantly different from those treated with higher concentrations of AEBSF at a $99.6 \%$ confidence level. For MTT assay results for primary mouse calvarial cultures, untreated controls $(\#), 0.003 \mathrm{mM}$ AEBSF wells $\left(^{\#}\right)$ and $0.03 \mathrm{~mm}$ AEBSF wells $\left(^{*}\right)$ were significantly different from those treated with 0.01 and $0.1 \mathrm{mM} \mathrm{AEBSF}$ at a 99.4\% confidence level. Results depicted are representative of 3 experiments. Error bars refer to the standard deviation of the mean. UMR culture studies were carried out in triplicate, while primary culture studies were done in quadruplicate. All analyses are based on a one-way analysis of variance comparison using a Student-Newman-Keuls multiple comparison test. From Huffman et al. [2007], reprinted with permission of the American Society for Biochemistry and Molecular Biology.

an approximately $106-\mathrm{kDa}$ active transmembrane form [Seidah and Chretien, 1999; Elagoz et al., 2002]. In specific circumstances, SKI-1 is transported to the plasma membrane, autocatalytically shed as an approximately 98-kDa catalytically active, soluble enzyme [Elagoz et al., 2002; Pullikotil et al., 2007]. The amount of $98-k D a$ form detected is similar in the total culture extracts and in the purified BMF preparation. While not indicative of a quantitative enrichment of SKI-1 to BMF complexes, our results demonstrate its association with structures mediating initial mineral nucleation. 


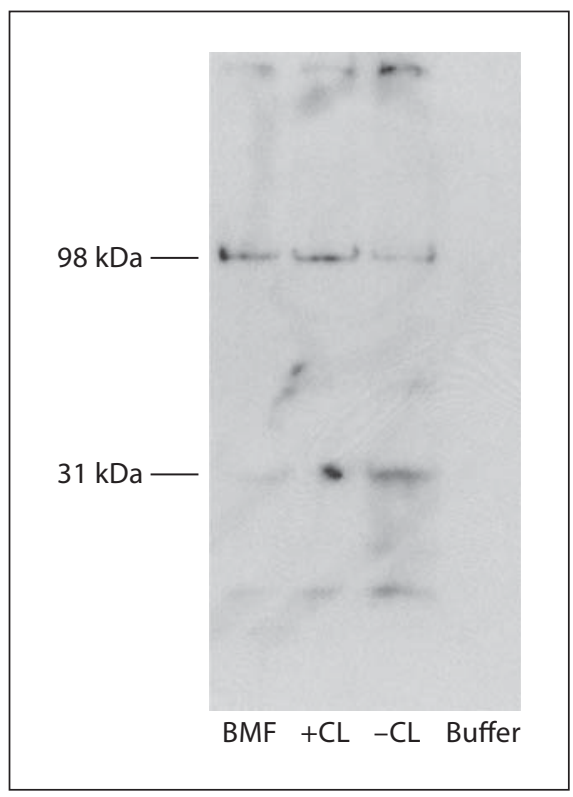

Fig. 4. Immunoblotting demonstrates the presence of SKI-1 in BMF and UMR 106 cultures. UMR cells were cultured on glass slides and resultant BMF were stained with alizarin red $S$ dye and purified using laser capture microscopy (see Experimental Procedures). As controls, the total cell layer fraction from a mineralized culture (+CL) and an unmineralized culture (-CL) were extracted separately and subjected to SDS-PAGE and immunoblotting along with laser microscopy-captured BMF or buffer alone. Identical amounts of protein were applied to each lane and probed with anti-SKI-1 antibodies.

\section{Discussion}

Serine proteases play a critical role in the activation and regulation of a number of biological processes in the extracellular environment, for instance, blood coagulation and complement activation. In this context, we hypothesize that the observed fragmentation of BAG-75 and BSP serves to activate their functional role(s) within BMF. While BSP is known to nucleate hydroxyapatite crystals, previous work has not shown a requirement for proteolytic activation [Goldberg et al., 1996]. We speculate that final assembly of nucleating complexes within BMF may require proteolytic fragmentation of BAG-75 and BSP. In all, we have identified 5 proteins whose cleavage is inhibited by AEBSF [Huffman et al., 2007].

PCs are comprised of 3 different groups of enzymes in terms of their substrate specificities [Seidah et al., 2006]. The 7 basic amino acid-specific convertases (PC1/3, PC2, furin, PC4, PC5/6, PACE4 and PC7), of which furin is the prototype, cleave preferentially following single or diba- sic sequences following the motif $(\mathrm{R} / \mathrm{K})-\mathrm{Xn}-(\mathrm{R} / \mathrm{K}) \downarrow$, where $\mathrm{n}=0,2,4$ or 6 amino acids, the 2 other convertases SKI-1/S1P and PCSK9 cleave at nonbasic residues after the motifs R-X-hydrophobic-X $\downarrow$ [Pasquato et al., 2006] and VFAQ $\downarrow$ [Benjannet et al., 2004; Seidah et al., 2006], respectively. Analysis of BSP, membrane-associated, rapid response steroid-binding (1,25-D3-MARRS) receptor and procollagen $\mathrm{C}$-proteinase enhancer protein 1 (PCOLCE), 3 proteins whose cleavage is blocked by AEBSF [Huffman et al., 2007], reveals each contains several SKI-1 candidate cleavage sequences which appear capable of generating the observed fragments [Huffman, Seidah and Gorski, unpubl. results]. SKI-1 is a type I membrane-bound protease synthesized as a $128-\mathrm{kDa} z y-$ mogen that is autocatalytically activated into transmembrane $106-\mathrm{kDa}$ forms and secreted soluble forms of approximately $98 \mathrm{kDa}$ [Seidah et al., 1999; Elagoz et al., 2002], both of which are inhibitable by AEBSF [Okada et al., 2003; Basak et al., 2004].

Evidence consistent with SKI-1's identity as the AEBSF-susceptible protease involves its known sensitivity to AEBSF, its association with mineralized BMF and its expression by mineralizing UMR cells as a predominant functionally active soluble enzyme of approximately $98 \mathrm{kDa}$ missing its C-terminal membrane-spanning domain. In UMR cells not treated with BGP, the relative content of active SKI-1 of approximately $98 \mathrm{kDa}$ is diminished and, instead, the prominent immunoreactive bands are $<35 \mathrm{kDa}$ (fig. 4). This suggests that SKI-1 itself can be proteolytically processed, particularly under nonmineralizing conditions, as was also observed in embryonic kidney cells [Pullikotil et al., 2007]. In contrast, results with specific inhibitors indicate that functional plasmin, thrombin, kallikrein, C1s complement protease and urokinase plasminogen activator are not required for mineral crystal nucleation within BMF (table 1).

In conclusion, our studies implicate SKI-1 as a serine protease-regulating mineral crystal nucleation within BMF complexes. Future studies will use siRNA knockdown and SKI-1 plasmid transfection approaches to conclusively identify SKI-1 as the AEBSF-susceptible protease associated with mineral nucleation in primary bone.

\section{Acknowledgements}

Supported by grant No. R01-AR052775 from the NIH NIAMS (to J.P.G.), a CIHR grant No. MOP 36496 and a Canada Research Chair No. 201652 (to N.G.S.). 


\section{References}

Basak, S., N.A. Stewart, M. Chretien, A. Basak (2004) Aminoethyl benzenesulfonyl fluoride and its hexapeptide (Ac-VFRSLK) conjugate are both in vitro inhibitors of subtilisin kexin isozyme-1. FEBS Lett 573: 186-194.

Benjannet, S., D. Rhainds, R. Essalmani, J. Mayne, L. Wickham, W. Jin, M.C. Asselin, J. Hamelin, M. Varret, D. Allard, M. Trillard, M. Abifadel, A. Tebon, A.D. Attie, D.J. Rader, C. Boileau, L. Brissette, M. Chretien, A. Prat, N.G. Seidah (2004) NARC-1/PCSK9 and its natural mutants: zymogen cleavage and effects on the low density lipoprotein (LDL) receptor and LDL cholesterol. J Biol Chem 279: 48865-48875.

Chen, Y., B.S. Bal, J.P. Gorski (1992) Calcium and collagen binding properties of osteopontin, bone sialoprotein, and bone acidic glycoprotein-75 from bone. J Biol Chem 267: 2487124878.

-Elagoz, A., S. Benjannet, A. Mammarbassi, L. Wickham, N.G. Seidah (2002) Biosynthesis and cellular trafficking of the convertase SKI-1/S1P: ectodomain shedding requires SKI-1 activity. J Biol Chem 277: 1126511275 .

Goldberg, H.A., K.J. Warner, M.J. Stillman, G.K. Hunter (1996) Determination of the hydroxyapatite-nucleating region of bone sialoprotein. Connect Tissue Res 35: 385-392.

Gorski, J.P. (1998) Is all bone the same? Distinctive distributions and properties of non-collagenous matrix proteins in lamellar vs. woven bone imply the existence of different underlying osteogenic mechanisms. Crit Rev Oral Biol Med 9: 201-223.

-Gorski, J.P., D. Griffin, G. Dudley, C. Stanford, R. Thomas, C. Huang, E. Lai, B. Karr, M. Solursh (1990) Bone acidic glycoprotein-75 is a major synthetic product of osteoblastic cells and localized as $75-$ and/or $50-\mathrm{kDa}$ forms in mineralized phases of bone and growth plate and in serum. J Biol Chem 265: 14956-14963.
Gorski, J.P., A. Wang, D. Lovitch, D. Law, K. Powell, R.J. Midura (2004) Extracellular bone acidic glycoprotein-75 defines condensed mesenchyme regions to be mineralized and localizes with bone sialoprotein during intramembranous bone formation. J Biol Chem 279: 25455-25463.

Huffman, N.T., J.A. Keightley, C. Chaoying, R.J. Midura, D. Lovitch, P.A. Veno, S.L. Dallas, J.P. Gorski (2007) Association of specific proteolytic processing of bone sialoprotein and bone acidic glycoprotein-75 with mineralization within biomineralization foci. J Biol Chem 282: 26002-26013.

Kimmel, D.B., W.S. Jee (1980) A quantitative histologic analysis of the growing long bone metaphysis. Calcif Tissue Int 32: 113-122.

Leighton, M., K.E. Kadler (2003) Paired basic/ Furin-like proprotein convertase cleavage of Pro-BMP-1 in the trans-Golgi network. J Biol Chem 278: 18478-18484.

Mark, H., A. Nilsson, U. Nannmark, B. Rydevik (2004) Effects of fracture fixation stability on ossification in healing fractures. Clin Orthop Relat Res 419: 245-250.

-Midura, R.J., A. Wang, D. Lovitch, D. Law, K. Powell, J.P. Gorski (2004) Bone acidic glycoprotein-75 delineates the extracellular sites of future bone sialoprotein accumulation and apatite nucleation in osteoblastic cultures. J Biol Chem 279: 25464-25473.

Okada, T., K. Haze, S. Nadanaka, H. Yoshida, N.G. Seidah, Y. Hirano, R. Sato, M. Negishi, K. Mori (2003) A serine protease inhibitor prevents endoplasmic reticulum stressinduced cleavage but not transport of the membrane-bound transcription factor ATF6. J Biol Chem 278: 31024-31032.

- Pasquato, A., P. Pullikotil, M.C. Asselin, M. Vacatello, L. Paolillo, F. Ghezzo, F. Basso, C. Di Bello, M. Dettin, N.G. Seidah (2006) The proprotein convertase SKI-1/S1P. In vitro analysis of Lassa virus glycoprotein-derived substrates and ex vivo validation of irreversible peptide inhibitors. J Biol Chem 281: 23471-23481.
Pullikotil, P., S. Benjannet, J. Mayne N.G. Seidah (2007) The proprotein convertase SKI-1/S1P: alternate translation and subcellular localization. J Biol Chem 282: 27402-27413.

- Seidah, N.G., M. Chretien (1999) Proprotein and prohormone convertases: a family of subtilases generating diverse bioactive polypeptides. Brain Res 848: 45-62.

Seidah, N.G., A.M. Khatib, A. Prat (2006) The proprotein convertases and their implication in sterol and/or lipid metabolism. Biol Chem 387: 871-877.

Seidah, N.G., S.J. Mowla, J. Hamelin, A.M Mamarbachi, S. Benjannet, B.B. Toure, A. Basak, J.S. Munzer, J. Marcinkiewicz, M. Zhong, J.C. Barale, C. Lazure, R.A. Murphy, M. Chretien, M. Marcinkiewicz (1999) Mammalian subtilisin/kexin isozyme SKI-1: A widely expressed proprotein convertase with a unique cleavage specificity and cellular localization. Proc Natl Acad Sci USA 96: 1321-1326.

- Seidah, N.G., A. Prat (2002) Precursor convertases in the secretory pathway, cytosol and extracellular milieu. Essays Biochem 38: $79-$ 94.

Steiglitz, B.M., M. Ayala, K. Narayanan, A. George, D.S. Greenspan (2004) Bone morphogenetic protein-1/Tolloid-like proteinases process dentin matrix protein-1. J Biol Chem 279: 980-986.

Turner, C.H., M.R. Forwood, J.Y. Rho, T. Yoshikawa (1994) Mechanical loading thresholds for lamellar and woven bone formation. J Bone Miner Res 9: 87-97.

Wang, A., J.A. Martin, L.A. Lembke, R.J. Midura (2000) Reversible suppression of in vitro biomineralization by activation of protein kinase A. J Biol Chem 275: 11082-11091. 